\title{
ANTONIL JURISTA? UMA CONTRIBUIÇÃO À HISTÓRIA DA LITERATURA JURÍDICA NO BRASIL COLONIAL NO SÉCULO XVIII
}

\author{
GustaVo CÉsAR MACHADO CABRAL ${ }^{1}$
}

RESUMO: Este artigo pretende discutir a relevância e o impacto da obra Cultura e opulência do Brasil por suas drogas e minas (1711), escrito pelo jesuíta João Antônio Andreoni sob o pseudônimo de André João Antonil. Apesar da sua grande relevância para muitos estudos sobre a história do Brasil, particularmente para os de história econômica, os aspectos jurídicos do livro ainda não receberam muita atenção. Assim, a análise será realizada a partir da reconstrução da história da literatura jurídica na Idade Moderna.

Palavras-chave: Brasil Colonial; Literatura jurídica; André João Antonil.

\section{Antonil jurist? A contribution to the history of the juridical literature in colonial Brazil in the $18^{\text {th }}$ century.}

ABSTRACT: This paper aims to discuss the relevance and the impact of the book Culture and opulence of Brazil by its drugs and mines (1711), written by the Jesuit João Antônio Andreoni under the pseudonymous of André João Antonil. Despite its great relevance to many studies on Brazilian history, particularly those related to economic history, juridical aspects of the book did not yet received much attention. This analysis will be done relating the book to the history of juridical literature during the Early Modern Age.

Keywords: Colonial Brazil; Juridical literature; André João Antonil.

\section{Introdução}

A relevância de Cultura e opulência do Brasil por suas drogas e minas no que diz respeito a vários temas centrais da vida na América portuguesa tornou praticamente obrigatórias as referências ao texto escrito por André João Antonil, pseudônimo do jesuíta de origem italiana João Antônio Andreoni (1649-1716, p. 33-34). Personagem importante do final do século XVII e início do século XVIII, Andreoni nasceu em Luca, na Toscana, estudou direito na Universidade de Perugia e ingressou na Companhia de Jesus em 1667. Chegou à América em 1681 a convite do padre António Vieira e não deixou mais o Brasil, ocupando postos de destaque na Companhia, como a Reitoria do Colégio da Bahia e o cargo de Provincial do Brasil, além de ter sido professor do Colégio e Visitador (Silva, 2007). Além do mais, Andreoni manteve uma relação próxima aos mais importantes círculos de poder da época, tendo sido confessor de dois gover-

\footnotetext{
${ }^{1}$ Doutor em História do Direito (USP). Professor da Faculdade de Direito da UFC. E-mail: gustavocesarcabral@gmail.com
} 
nadores-gerais e pessoa de confiança do Arcebispo D. Sebastião Monteiro da Vida, que Ihe incumbiu de ser nada menos do que censor e revisor das Constituições Primeiras do Arcebispado da Bahia (Leite, 1949, p.113-114;120-121).

Andreoni e o seu Cultura e opulência já foram objeto de diversas reflexões sobre temas importantes para a história colonial brasileira, do que resulta uma bibliografia bastante extensa e rica. Retratos de um Antonil, para usar o pseudônimo impresso na capa da primeira edição do livro, de 1711, economista, moralista, pedagogo ou interessado em agricultura e mineração não são difíceis de se encontrar nos muitos textos dedicados à sua obra. Ao contrário, esses perfis são bastante comuns. Há, no entanto, uma lacuna bastante significativa nas análises desse personagem: houve um Antonil jurista?

A pergunta está longe da obviedade. O fato de Andreoni ter estudado direito e de ter participado do processo de elaboração das Constituições Primeiras são indicativos de que houve um componente jurídico na sua multifacetada personalidade, o que não seria propriamente de se estranhar em contexto em que, longe de uma pureza temática, o direito precisa ser compreendido como um fenômeno que se relacionava profundamente com vários setores do conhecimento, a exemplo do que ocorria com a retórica - arte da qual, inclusive, Andreoni fora professor - e da teologia moral. Os temas se comunicavam de um modo em que uma separação clara, nesse contexto, não era possível ${ }^{2}$. Diante disso, Serafim Leite chamou a atenção para uma discussão jurídica e moral empreendida em Cultura e opulência sobre a tributação, em uma rara referência a essa perspectiva (Leite, 1949, p. 184-188).

A proposta deste trabalho é justamente oferecer uma análise do perfil de jurista de Antonil, o que implica necessariamente o foco na obra Cultura e opulência do Brasil por suas drogas e minas. Este artigo tem como preocupação principal a obra em si, justamente por fazer parte de uma tentativa mais ampla de se analisar a existência e as características da literatura jurídica na América Portuguesa. A hipótese central é que a obra de Antonil pode ser de interesse para a literatura jurídica colonial. Assim, depois de discutir alguns elementos relacionados à obra em si e também de apresentar sucintamente o que se entende por literatura jurídica nesse contexto, passa-se a uma análise mais minuciosa do trecho de Cultura e opulência que interessa a esse debate.

\footnotetext{
${ }^{2}$ Nessa perspectiva, entre outros, (Decock, 2013).
} 


\section{A história de um livro}

Cultura e opulência do Brasil por suas drogas e minas é uma das obras mais importantes dentre as escritas na América Portuguesa. Sua divisão interna contempla as quatro atividades econômicas mais importantes no Brasil da transição do século XVII para o XVIII, que eram justamente o açúcar, o tabaco, a mineração e a pecuária. Por se tratar de obra em que a questão econômica aparece como estrutural e diante do fato de que há vários temas sobre os quais não existem tantas informações disponíveis, a consulta à obra acontece com frequência porque ela serve de referência sobre diversos aspectos da vida colonial.

Alguns dados apresentados no texto são preciosos para o conhecimento de detalhes da economia colonial, como informações sobre os custos das caixas de açúcar nas capitanias do atual nordeste brasileiro no período analisado, inclusive porque, como afirmou Stuart Schwartz, o texto parece ser muito mais uma descrição viva da vida colonial do que propriamente uma crítica (Schwartz, 2012, p. 13). Como se trata de dados que não são tão facilmente encontrados em outras fontes, essas informações costumam ser utilizadas em estudos que abordem o assunto. Exemplo disso foi um artigo de Pedro Puntoni sobre a provedoria-mor, em que o autor empregou esses dados e os utilizou conjuntamente com outras fontes documentais (Puntoni, 2013, p. 141-144).

O tema da escravidão em Antonil vem sendo trabalhado com muita qualidade há bastante tempo, do que resulta uma vasta bibliografia dedicada tanto ao estudo específico do tema diretamente em Cultura e opulência quanto em uma perspectiva comparada com outras obras do período. Há muitos elementos comuns entre os textos que trabalham com a escravidão negra, o que faz com que se percebam muitos elementos comuns entre as obras de Antonil e de outros jesuítas, como Jorge Benci e Manoel Ribeiro da Rocha. Aparecem em todos os textos, por exemplo discussões sobre a legitimidade da posse dos cativos desde a sua captura em África até o momento do comércio negreiro, assim como as obrigações dos senhores para com os seus escravos (Pessoa, 2008, p. 223-247). É nesse contexto que obras seminais como as de Ronaldo Vainfas e Rafael Marquese se destacam por uma leitura mais ampla de Antonil e do tema da escravidão no início do século XVIII (Vainfas, 1986; Marquese, 1999; Marque- 
se, 2014).

Partindo do fato de que parte do livro foi dedicada ao estudo do senhor de engenho e de seus dependentes, em uma tentativa de compreender a dinâmica das relações sociais nas regiões em que há forte presença da cultura açucareira, a análise da escravidão aparece como uma questão estrutural em Cultura e opulência. Ronaldo Vainfas se refere a um processo de justificação da escravidão a partir da expiação dos pecados dos escravos, ainda que a obra em análise inclua uma crítica acentuada às práticas da escravidão pelos senhores (Vainfas, 1986, p. 134-141). As ideias de Antonil, que compõem o projeto jesuíta que se manifesta pela sua intelectualidade, são formuladas de modo "perfeitamente adequado à sua condição de senhores e missionários, legitimando simultaneamente a escravidão e a doutrina cristã" (Vainfas, 1986, p. 157), o que faz sentido quando se pensa que tanto Antonil quanto Benci se dirigiram aos senhores, e não aos escravos, quando condenavam as praticas abusivas nos castigos (Zeron, 2011, p. 341). Como menciona Andrée Mansuy Diniz Silva, a intenção de Antonil era escrever um texto simples, claro e facilmente compreensível ao seu público (Silva, 2007, p. 51). Desta forma, conhecer a obra de Antonil é fundamental para se ter acesso a uma parte significativa da justificativa da escravidão pelos jesuítas, de modo que os vários trabalhos dedicados a essa perspectiva comparada entre Antonil, Benci, António Vieira e outros jesuítas parte do pressuposto, facilmente comprovável, de que há muitos pontos convergentes entre esses autores (Dias, 2012; Ambires, 2008).

Outros temas também são explorados em Cultura e opulência. A questão do espaço associado à produção econômica (no caso, agrícola), com ênfase na questão da casa e do governo doméstico (oikonomia), tema caro à historiografia influenciada por autores como Otto Brunner (1959) ${ }^{3}$, é muito relevante na obra de Antonil. Para o jesuíta, a imagem do senhor, segundo Vainfas, se constrói enquanto autoridade patriarcal em que a posse e o poder se confundem na figura do dominus e se estendem tanto às coisas como às pessoas (Vainfas, 1986, p. 135). Muito claramente, Antonil afirma, em uma passagem bastante conhecida, que o senhor de engenho se equipara aos fidalgos do reino ${ }^{4}$. É nesse sentido o texto de Guilherme Amaral Luz sobre as relações entre

\footnotetext{
${ }^{3}$ Ainda sobre a noção de casa, (Seelaender, 2017).

${ }^{4}$ "E se for, qual deve ser, homem de cabedal, \& governo; bem se pode estimar no Brasil o ser Senhor de Engenho, quanto proporcionadamente se estimaõ os Titulos entre os Fidalgos do Reyno". (Antonil, 1711), fol. 1, Liv. I, Cap. I.
} 
Antonil e o também jesuíta Prudêncio Amaral no que diz respeito ao governo do engenho (Luz, 2008). Por sua vez, um olhar sobre natureza, notadamente quanto à atividade mineira, é o foco principal de um estudo de Francisco Eduardo de Andrade em que Antonil e o também setecentista Sebastião da Rocha Pita surgem como pontos de comparação (Andrade, 2006).

No entanto, algumas questões polêmicas rondaram essa obra, não sob um ponto de vista interno, de conteúdo, mas sob um ponto de vista estrutural. A primeira delas dizia respeito à autoria do texto, tendo em vista que o André João Antonil mencionado na folha de rosto do livro e a quem o prefácio se refere como "O Anônimo Toscano" foi uma figura fictícia. Coube a Capistrano de Abreu, somente nas primeiras décadas do século XX, identificar em Andreoni o verdadeiro autor do texto, conforme comprovam cartas trocadas entre o historiador e Afonso d'Escragnolle Taunay, que por sua vez escreveu um estudo sobre o autor de Cultura e opulência (Taunay, 1923).

Andrée Mansuy Diniz Silva retratou o processo de escrita da obra. Como já se mencionou, Andreoni, para além da sua formação jurídica em universidades italianas, manteve-se, durante praticamente toda a sua permanência no Brasil, próximo aos principais centros de poder colonial, o que lhe garantiu o acesso à cultura letrada disponível. Por outro lado, para escrever a primeira parte da obra, dedicada ao açúcar e à sociedade açucareira, parece ter sido fundamental a sua relação de proximidade com a atividade econômica, especialmente porque, em todo o tempo em que viveu na América, Andreoni morou na Bahia, região em que a cultura do açúcar foi muito desenvolvida. Andrée Mansuy Diniz Silva, no entanto, argumenta que fora decisiva a experiência de Andreoni no engenho de Sergipe do Conde, que era de propriedade dos jesuítas, por algumas semanas, momento em que o autor pode verificar na prática a lógica da produção açucareira (Silva, 2007, p. 38-39). O início da escrita da primeira parte do texto, inclusive, remonta a essa estadia no engenho (Silva, 2007, p. 43); a determinação das épocas precisas em que as quatro partes da obra foram escritas, contudo, não é tarefa das mais óbvias. Para chegar a um possível cronograma de execução, Andrée Mansuy Diniz Silva parte de um estudo das tabelas de preços apresentadas ao longo do texto para indicar que a primeira parte, referente ao açúcar, teria sido escrita entre 1693 e 1698 e atualizada entre 1704 e 1707, ao passo que as outras três partes teriam sido executadas entre 1707 e 1709 (Silva, 2007, p. 47). 
Por fim, a história do livro em si. A edição original de Cultura e opulência saiu da tipografia em 1711, mas, mesmo tendo obtido as licenças necessárias para a impressão e a circulação, acabou sendo integralmente recolhida por ordem régia. Exatamente catorze dias depois da concessão da última licença pelo Desembargo do Paço, no dia 17 março de 1711, o Conselho Ultramarino propôs o recolhimento e a destruição do texto (Silva, 2007, p. 53). Após décadas de discussão sobre as razões para essa decisão ${ }^{5}$, a explicação mais consistente foi feita por Laura de Mello e Souza: a parte que tratou da mineração poderia representar um risco por indicar o caminho para se chegar às minas, o que, no contexto do início do século XVIII, significaria uma ameaça de invasão ao Brasil, daí porque o recolhimento da obra significaria manter os caminhos paras minas em segredo (Souza, 2006, p. 84-98). Assim, destruíram-se os livros antes que fossem postos à circulação, não restando mais do que sete cópias da edição original de 1711 (Silva, 2007, p. 25-26).

Uma conclusão a que se pode chegar da ordem de recolhimento é que existia plena consciência do poder do conteúdo do livro, que consistia em um importante suporte para a circulação de informações nesse contexto. Proibir um livro, com os subsequentes recolhimento e destruição, representava uma forma de controle pela Coroa que poderia garantir a inacessibilidade à informação e, assim, a manutenção do estado das coisas.

\section{Existe uma literatura jurídica no Brasil colonial?}

O direito erudito manifestado por meio da literatura jurídica na América Portuguesa não é dos temas mais comumente observados entre os estudos dedicados ao período. Algumas características desse espaço jurídico ajudam a compreender as razões dessa falta de atenção: população majoritariamente analfabeta, incluindo muitos dos que ocupavam ofícios jurisdicionais; ausência de universidades, que funcionariam justamente como centros produtores de um conhecimento jurídico culto; proibição da existência e do funcionamento de imprensa, o que tornava mais complicada a impressão e consequentemente a circulação do livro. Essas barreiras tornaram difícil a formação de um amplo espaço para uma cultura jurídica erudita, ao mesmo tempo em que

\footnotetext{
${ }^{5}$ As principais opiniões podem ser encontradas em (Silva, 2007, p. 53-62).
} 
foi vasto o espaço para uma cultura jurídica mais popular, no sentido do que António Manuel Hespanha chamou de "mundo dos rústicos" (Hespanha, 2017a).

Na América hispânica, uma conjuntura diferente, com um maior espaço para o direito letrado, possibilitou o aparecimento de juristas como Juan de Solórzano Pereira (1575-1653), Juan de Matienzo (1520-1579), Feliciano de Vega (1580-1640), Diego de Avendaño (1594-1698), dentre outros, cujas obras, por mais que tenham sido escritas na América e pensadas a partir de problemas locais, foram editadas na Europa, onde circularam e ganharam notoriedade. Essas diferenças estruturais, que se observam, por exemplo, quando se percebe que as primeiras universidades na América hispânica antecederam em quase trezentos anos as primeiras faculdades de direito no Brasil, ajudam a entender porque o estudo de uma literatura jurídica na América portuguesa precisa observar outros parâmetros. Os textos escritos aqui atendem primordialmente a uma outra linha de interesses, longe das obras sobre grandes temas que se observou na literatura jurídica europeia e, em escala menor, também na América hispânica.

Para entender os fundamentos dessa literatura, faz-se necessário compreender os elementos centrais do direito na Idade Moderna. Um olhar para o pluralismo é um primeiro passo importante, já que havia vários centros de produção normativa para além do direito régio (Hespanha, 2017b), que funcionava como uma espécie de direito comum do reino, como afirmavam os juristas da época ${ }^{6}$. Longe de uma perspectiva sistemática, o direito na Idade Moderna era marcado pelo casuísmo, em que o fundamental era propor soluções para problemas concretos. Essas soluções não deveriam ser compatíveis com respostas para outros problemas ${ }^{7}$, tal qual se tornou necessário a partir da consolidação, com as revoluções liberais, da noção de que o Estado seria o único centro de produção normativa, fazendo surgir a ideia de sistema jurídico e, consequentemente, da necessidade de coerência sistêmica. Assim, a principal característica do direito nesse contexto parece ter sido, sob uma perspectiva de multinor-

\footnotetext{
6 "Ius regium, ius commune est in regno". (Gama, 1683), p. 97 (Dec. L, 5). "Nostrum ius regium est nostrum ius commune. Lusitani non possunt consentire in Principem non suum". (CASTRO, 1621), p. 10 (Dec. II).

${ }^{7}$ Nesse sentido, (Tau Anzoátegui, 1992). Essa perspectiva casuística se manifestava com muita força na legislação, como se percebe da estrutura das cédulas reales no direito de Castela ou mesmo nas cartas régias portuguesas: mais do que uma motivação para solucionar problemas em geral, o fundamental na edição dessas leis era a necessidade de se resolver um problema concreto.
} 
matividade ${ }^{8}$, o seu papel para a resolução de conflitos. A fim de se alcançar essa resolução, vários elementos de outras áreas do conhecimento contribuíam decisivamente, diferentemente da pureza defendida como necessária ao direito ao longo de século XX por autores como Hans Kelsen (1934).

Os temas que interessavam ao direito também eram relevantes em outras áreas do conhecimento, em especial a teologia moral, que era justamente a parte da teologia preocupada com o oferecimento de respostas para problemas concretos observados em uma realidade particular ${ }^{9}$. A análise dos conteúdos de alguns dos mais importantes manuais de teologia moral editados entre os séculos XVI e XVIII, como a Theologia moralis de Paul Laymann (1574-1635) e De justitia et jure de Domingo de Soto (1494-1560), demonstra claramente que se discutiam temas com relevância também para o direito, a exemplo das definições de lei humana, de justiça e de direito, crimes, obrigações e contratos, testamentos e casamentos, no primeiro, relações entre direito humano e direito divino, justiça distributiva e justiça comutativa, homicídio e usura, no segundo. A intenção primordial desses cursos, que foram ministrados na América portuguesa nos colégios de jesuítas, era possibilitar àqueles que os frequentassem a capacidade de decidirem problemas concretos que lhes surgissem.

É olhando para esses pontos que se percebe muito claramente a existência de uma literatura jurídica na experiência colonial, que, é fundamental ressaltar, teve bases firmadas na experiência da literatura jurídica europeia ${ }^{10}$, mas que buscou resolver problemas típicos da realidade local. Foi uma literatura interessada em dar ao particular as soluções adequadas para os seus casos, sem, contudo, se desvencilhar da tradição em que estava inserida. Por essas razões, a cultura jurídica letrada que se formou na América Portuguesa guarda relação direta com a tradição europeia, constituindo-se uma verdadeira área de expansão dessa tradição ${ }^{11}$.

A discussão que se faz neste texto se situa em um projeto maior, dedicado a compreender as bases da formação dessa literatura jurídica na América portuguesa, especialmente olhando para a questão prática da resolução de problemas concretos e

\footnotetext{
${ }^{8}$ Para uma visão do tema, (Duve, 2017, p. 88-101).

${ }^{9}$ Nesse sentido, (LEITE, 1949, p. 175-189).

10 Para uma discussão geral sobre a literatura jurídica europeia da transição do Medievo até o Antigo Regime, entre outros, (Cabral, 2017, p. 175-189).

${ }^{11}$ Nesse sentido, (Duve, 2012, p. 18-71).
} 
de casos de consciência ${ }^{12}$. Em todos os textos dedicados ao tema, buscou-se analisar a questão a partir de dois pilares centrais, a saber, a produção de uma literatura jurídica local e a circulação no espaço local de uma literatura jurídica. De um lado, analisou-se a existência de obras de interesse jurídico, conceito que alcança textos que tratassem de temas relevantes para o direito, ainda que tenham sido escritas por teólogos, produzidas no espaço colonial; de outro, buscou-se analisar, a partir dessas obras, a existência de um espaço letrado em que circulavam obras jurídicas, não necessariamente as obras produzidas no espaço local, mas, principalmente, os textos ligados à tradução jurídica europeia que se encontravam nos restritos espaços para o direito letrado formal.

E é a partir desses dois pilares que se realizará este estudo. Da mesma forma que textos juridicamente relevantes como Se um pai pode vender o seu filho ou vender a si mesmo (1567), de Manuel da Nóbrega, o anônimo Apologia pro paulistis (1694), Brasilia pontificia (1747), de Simão Marques, entre tantos outros, há uma clara relevância para o direito em Cultura e opulência no Brasil e suas drogas e minas. Se o fato de o livro impresso em 1711 praticamente não ter circulado em virtude da já comentada proibição dificulta a verificação do impacto da obra na literatura jurídica colonial, é plenamente viável pensar essa questão a partir do conteúdo do texto, revelador de que Andreoni, ao escrevê-lo, se preocupou em construir uma obra dedicada às particularidades e aos problemas locais, utilizando-se para isso, como se verá, de uma argumentação completamente inserida na tradição jurídica europeia.

\section{A discussão jurídica em Cultura e opulência}

\subsection{A atividade minerária e o seu regime jurídico}

O momento juridicamente relevante de Cultura e opulência no Brasil e suas drogas e minas se situa no livro III, que é dedicado à mineração. Mais especificamente o capítulo IX, intitulado "Da obrigação de pagar a El-Rey nosso Senhor a quinta parte

\footnotetext{
${ }^{12}$ Para uma descrição do projeto "Pragmatische Literatur im portugiesischen Amerika (16.-18. Jahrhundert)" (Literatura pragmática na América Portuguesa, séculos XVI-XVIII). Disponível em: $<$ http://www.rg.mpg.de/forschung/pragmatische-literatur-im-portugiesischen-amerika $\geq$. Acesso em: $13 / 10 / 2017$.
} 
do Ouro, que se tira das Minas do Brasil". É essencialmente sobre esse trecho do livro que este estudo se debruçará daqui em diante.

Logo no início da discussão, Antonil enuncia que a análise do tema central pode se dar tanto sob a perspectiva das Ordenações do Reino, que representariam o direito positivo, quanto pelo foro interno, por questão de consciência (Antonil, 1711, p. 146). Não é estranha essa aproximação entre os foros externos e internos, ou seja, direito, de um lado, e moralidade e consciência do outro. Muito ao contrário. Uma das marcas da Idade Moderna foi justamente a manutenção dessa relação próxima, não havendo uma separação muito nítida entre os dois foros. As muitas ligações entre forum internum e forum externum de que tratou Wim Decock demonstram como eram próximas e como se influenciavam mutuamente as duas ordens (Decock, 2013, p. 2728), em uma relação que começa a se desfazer a partir da Reforma e das guerras religiosas. No plano teórico, apenas com a contribuição de autores como Christian Thomasius é que se consolida a ideia de que o direito não deveria se preocupar com questões de consciência ${ }^{13}$. A perspectiva de Antonil se situa na tradição de aproximação entre os dois foros, o que explica esse seu postulado inicial.

Segue com referência direta, inclusive com transcrição, de trechos das Ordenações contidos no Liv. 2, Tit. 26, $\$ 16$ e Liv. 2, Tit. 28. Fala-se também que o rei, a fim de incentivar a atividade minerária e, consequentemente, a descoberta de novas minas, pode, além de explorá-la diretamente, permitir que os seus vassalos as explorem, desde que paguem o quinto, que seria justamente uma espécie de participação da Coroa nos lucros dessa atividade. Segue com citações das Ordenações sobre a necessidade do procedimento de marcação do ouro depois do recolhimento do quinto e sobre as penas (perdimento do ouro e degredo por dez anos) aplicáveis caso não se realize o pagamento do outro (Antonil, 1711, p. 147).

Há uma discussão importante no trecho em que Antonil afirma que as minas compõem os direitos régios e seriam, portanto, inalienáveis, tais quais os demais bens relacionados no já comentado Liv. 2, Tit. 26, das Ordenações. É categoria dos chamados direitos reais, que, na síntese de António Manuel Hespanha, seriam, "os direitos que competem ao rei enquanto pessoa pública", que seriam distintos dos "direitos que os particulares (ou o rei, enquanto particular) tinham uns em relação aos outros em

\footnotetext{
${ }^{13}$ Sobre o tema, (Cabral, 2016, p. 145-167).
} 
virtude de pactos, daqueles direitos que o rei tinha em relação aos vassalos por imposição da lei ou do costume" (Hespanha, 2015, p. 98). Como fundamentação, Antonil trouxe as opiniões de juristas importantes como Pedro Barbosa, Jorge de Cabedo, Manuel Álvares Pegas, Lucas de Penna, Pierre Rebuffi e Juan de Solórzano Pereira, assim como as opiniões dos teólogos Luís de Molina, Padre Vasquez e Cardeal Juan de Lugo. Referências diretas às obras são comuns, mas, em alguns casos, Antonil se utilizou de transcrições dos textos.

Pegas, citado por Antonil, reconheceu a possibilidade de o rei fazer concessões de direitos sobre as minas, que, por serem regalias, não poderiam ser vendidos aos particulares ${ }^{14}$. Os fundamentos da sua opinião foram encontrados em autores mencionados também por Antonil, como Lucas de Penna, Pierre Rebuffi e Pedro Barbosa, mas também em dois importantes autores da tradição dos consilia italianos, Paulo de Castro e Mariano Soccino. Já o trecho em que Antonil cita de Jorge de Cabedo, trata especificamente da venda de metais, e nele, Cabedo, depois de se referir às opiniões de Pedro Barbosa e de Matteo D’Afflito, transcreveu uma decisão da Casa da Suplicação sobre a necessidade de recolhimento de tributos sobre o ferro extraído de uma mina e da apresentação de licença régia que autorizasse a atividade ${ }^{15}$.

Dentre os teólogos consultados, mencionam-se as opiniões de Molina e de Lugo. Molina escreveu um texto importante na sua Disputatio 54 em De iustitia et iure sobre o regime jurídico dos minérios, partindo do tratamento legislativo em Castela e da opinião principalmente de juristas que comentaram o direito positivo castelhano, com destaque para António Gómez, para reconhecer o direito do senhor de receber um determinado valor a partir da exploração minerária (Molina, 1614, p. 241-244, Tract. 2, disput. 54). Situando a discussão no domínio de bens descobertos, o Cardeal Lugo tratou diferentemente os casos em que a descoberta se desse em locais públicos, caso em que o domínio da descoberta dos metais seria do primeiro ocupante, ou no

\footnotetext{
14 “Hoc vero jus Regale competit Principi pro Camer Imperij ad sustinenda onera Reipublicae. Er ideo nec à Principe alienari potest, ne alias destruatur Imperium. (...) Et ideo merito statutum est, quod hoc jus Regale in generali concessione Regalium nõ veniatni, si expressim, \& in indiuiduo illius fiat mentio, \& fact expressa concessione fudinarum metallorum, an omnes veniant ujuscunque specie". (Pegas, 1684, p. 277-278, Lib. II, tit. 28, 24).

15 “Acordão em Relação, \&e. que he bem julgado pelo Provedor em condemnat o R. Duarte Luis que pague decima do ferro que tem tirado nas minas a contenda, do tempo da lide contestada em diante: confirmão sua sentença per alguns de seus fundamentos \& pelo mais que dos autos se mostra, com declaração que daqui em diante não minará nas ditas minas sem licença do dito senhor sob pena dela, \& seja sem custas por ser entre o dito senhor \& seus vassalos". (Cabedo, 1699, p. 22, Dec. LV, 2).
} 
subsolo, quando, por sua vez, seria do descobridor. Entretanto, baseado nas opiniões de Domingo de Soto e de Leonard Lessius, Lugo afirmava que leis régias poderiam instituir mecanismos de compensação para os casos de descobertas de minérios no subsolo (Lugo, 1652, p. 147, Disp. VI, Sect. X, 106). Por meio de um tributo sobre a mineração, que funcionava justamente como esse mecanismo de compensação pela atividade, o rei estava reservando para si a titularidade das minas (Lugo, 1652, p. 147, Disp. VI, Sect. X, 108).

\subsection{A legitimidade da titularidade do domínio do Novo Mundo}

A conclusão a que chegou Lugo vai justamente ao encontro do que estabeleceram as Ordenações do Reino sobre a natureza das minas em Portugal. Tendo essa ideia como pressuposto e baseando-se na estrita observância do direito régio, Antonil via como devido e justo que se pagasse o imposto que em Portugal ficou conhecido como quinto, o qual deveria incidir sobre o valor bruto do metal extraído da terra ${ }^{16}$. Argumenta também que esse regime previsto para as minas do reino deveria ser obedecido em Ultramar, notadamente no Brasil. Nesse sentido, Antonil utiliza a opinião de Juan de Solórzano Pereira e de Diego de Avendaño, dois dos mais importantes autores do chamado derecho indiano, que acabaram por explicar como esses casos eram regidos para a América hispânica.

Para explicar o exercício da jurisdição temporal e espiritual nas Índias, Solórzano Pereira faz uma longa discussão a partir de vários instrumentos normativos oriundos do poder papal, mas trazendo também em seu texto vários atos dos reis para as reales audiéncias no Novo Mundo, notadamente para México e Lima, para além da presença muito forte de citações de juristas do direito comum (Pereira, 1672, p. 406419, Lib. II, Cap. XXIV). Antonil ainda afirma que é possível encontrar bons fundamentos para essa questão em toda a segunda parte e nos primeiros capítulos da terceira

\footnotetext{
16 "Ou se considerem pois as Minas como parte do Patrimonio Real, ou como justo Tributo para os gastos em prol da Republica, he certo, que se deve a El-Rey o que para si reservou, que he a quinta parte do Outro, que dellas se tirar, puro, \& livre de todos os gastos: \& que o que se manda nas Ordenaçoens acima referido, está justamente ordenado: \& q prescindindo de qualquer pen, o quinto ex natura rei se lhe deve naõ menos, que outro qualquer justo tributo, ordenado para bem da Republica, ou como cobra a pensaõ, que impoemsobre qualquer outra parte do seu Patrimonio, como he a que se lhe deve, $\&$ se Ihe paga dos Feudos". (Antonil, 1711, p. 150).
} 
parte da obra De indiarum iure de Solorzáno Pereira, mas as referências mais diretas ao livro quinto do segundo volume dessa obra são bastante esclarecedoras. Solorzáno Pereira afirmou que os metais são patrimônio régio ${ }^{17}$ e que a sua descoberta é muito útil à república ${ }^{18}$, inclusive porque da extração se pode cobrar o imposto do quinto ${ }^{19}$.

Outro autor importante para a construção do argumento de Antonil neste ponto foi Diego de Avendaño. No seu Thesaurus Indicus, Avendaño inicia a discussão com a construção da legitimidade do Papa para fazer a doação das terras da América aos reis de Portugal e de Castela, tratando especificamente do caso português em uma referência ao Papa Alexandre $\mathrm{VI}^{20}$. Neste momento, a principal obra utilizada foi o Tractatus de potestate summi pontificis in rebus temporalibus do Cardeal Roberto Belarmino. A seguir, Avendaño apresenta os fundamentos para essa doação, valendo-se principalmente das obras de Tomás de Aquino e de Francisco Suárez (Avendaño, 1668, p. 4-5, Tit. I, Cap. I, §3).

Antonil buscou apresentar argumentos para afirmar a legitimidade do poder régio no Novo Mundo, em uma discussão que também foi feita por outros autores ligados à América, os quais foram utilizados para fundamentar a sua opinião. Deste modo, sendo legítima a autoridade papal para doar o domínio e garantir a conquista do Brasil aos reis de Portugal, provar-se-ia, de modo indubitável, "a justiça, com que se acquirio, \& se conserva o domínio, \& posse destas Conquistas" (Antonil, 1711, p. 151).

\subsection{Legitimidade da cobrança do quinto}

Superada a discussão quanto à titularidade do domínio da Coroa Portuguesa

\footnotetext{
17 "Sunt porro haec Metalla, sive Minerae, tam in his provincijs, quam álibi, de Regalibus, hoc est ad ius, patrimonium, \& supremam Regis ditionem pertinentes, sive illae in publicis, sive in privatis praedijs reperiantus, adeo, ut neque in concessione sun li, vel territorij, quantumvis generaliter facta, contineantur, nisi specialis earum mentio fiat". (Pereira, 1672, p. 1061, p. II, lib. V, Cap. 1, 19).

18 "Sed nihilominus, quo sint plures, qui eiusmodi fodinis earumque metallis quarendis, effodiendis, \& laborandis occupentur, quod quam situ tile, \& necessarium dixi supra ho tom. lib.l.cap.13. ex num. 33.\& quia re vera hi homines, qui in metallis, \& thesauris investigantis occupantur, Reipublicae utilissimi sunt". (Pereira, 1672, p. 1061, p. II, lib. V, Cap. 1, 20).

19 “(...) ita tamen, ut Regi praecise quintm partem omnium metallorum, quae extrxerint, praestare teneantur, neque eis aliter uti possint, quam si Regium signum, sive stigma, illis inustum sit, per quod de solutione quinti constare possit". (Pereira, 1672, p. 1061, p. II, lib. V, Cap. 1, 23).

20 "Ex hoc enim habemus donatione \& inuestituram in terris Indiarum non à solo Alexandro Sexto factam, sed etiam aliàs à Sede Apostolica diueris Portugalliae Regibus: vt iterata huiusmodi concessio jus arguat in illa non dubium, sed iuiolabili subnixum veritati". (Avendaño, 1668, p. 2, Tit. I, Cap. I, §1, 4).
} 
na América, Antonil volta a tratar do quinto, olhando essencialmente para a questão da legitimidade da sua cobrança. O elenco de autores mencionados por Antonil para defender que entre os frutos da terra estavam os metais e, consequentemente, sobre eles seria possível incidir a cobrança do quinto é bastante significativo. Destacam-se as menções a De expensis et meliorationibus commentarius de Juan García de Saavedra, especialmente na parte em que trata das doações remuneratórias relacionadas ao ouro (Garcia de Saavedra, 1668, p. 760-762, Cap. XXII, 47). Ademais, os nomes de Jorge de Cabedo, Prospero Farinacci, Cardeal Thuscus e Pierre Rebuffi aparecem para corroborar a tese de que os minérios, "como os outros frutos da Terra, estaõ sujeitos ao dizimo, que os Papas concederaõ aos Reys de Portugal, \& aos de Castella", bem como justificam a imposição aos mineiros "que lhe paguem a quinta parte do outro, \& prata que tiraõ de suas Minas, eu saõ parte do seu Patrimonio, \& parte sempre reservada, como está dito" (Antonil, 1711, p. 152-153).

\subsection{Pagamento de dívida tributária e obrigação de consciência}

A grande questão do referido capítulo diz respeito à natureza da obrigatoriedade do pagamento do quinto. Antonil se propõe a discutir se o pagamento do quinto decorre ou não de uma obrigação de consciência. A previsão de penas temporais duras (perdimento de bens e degredo por dez anos) para o caso de não pagamento da dívida tributária poderiam, segundo o autor, fazer pensar que se trataria de uma lei meramente penal e que não obrigaria em consciência.

Antonil buscou primordialmente nos teólogos a resposta para essa dúvida. 0 primeiro autor trazido foi Francisco Suárez, que discutiu exatamente a natureza das leis que impõem tributos. Tanto os tributos sobre pessoais quanto os que incidiam sobre coisas eram reais por serem instituídos em honra dos reis (Suárez, 1613, p. 352, Lib. V, Cap. XIII, 2) e deveriam ser pagos por uma questão de justiça, justamente por serem de propriedade dos reis (Suárez, 1613, p. 352, Lib. V, Cap. XIII, 3). Suárez também se pergunta se as leis que instituem tributos seriam meramente penais, apesar de instituírem penas, e a resposta se relaciona justamente ao fato de ser por justiça, especificamente por justiça comutativa, que se deve adimplir a dívida tributária: as leis 
que instituem tributos também obrigam em consciência ${ }^{21}$.

Suárez foi uma das maiores autoridades da neoescolástica espanhola dos séculos XVI e XVII, e suas obras tiveram grande impacto nos teólogos e canonistas da Companhia de Jesus, inclusive entre os que atuaram na América portuguesa. O caso de Antonil é exemplar disso, uma vez que, como se percebe, a sua opinião foi primordial tanto para que o autor colocasse a questão central deste ponto do livro quanto para a resposta que foi estruturada. A ideia de justiça comutativa, elemento essencial da teoria aristotélica da justiça que se repete no pensamento escolástico, seria a principal explicação para essa razão de consciência que cerca as leis penais. Sendo o rei de Portugal senhor das minas, ele poderia usá-las como se utiliza o próprio patrimônio para desses bens retirar "a sua sustentaçaõ, \& gastos que faz em prol da Republica, \& para a conservação \& aumento da Fé" (Antonil, 1711, p. 154). Logo, a forma de compensar o rei como senhor dos bens era justamente por meio da imposição de tributos, que seriam um modo de dar a cada um (ao rei) o que era seu (recursos pela exploração do seu patrimônio), materializando-se a ideia de justiça comutativa.

Em suma, Suárez apresenta três razões principais para a sua posição: o fato de haver imposição de pena não desnatura a natureza moral de leis que tratem da república; a certeza moral não dependia da previsão das penas, que apenas garantiriam a eficácia da lei; e a matéria era relacionada à justiça por se tratar de assunto de governo e da conservação da república, que são essencialmente morais ${ }^{22}$. Essas razões foram transcritas e enfatizadas por Antonil, que afirma expressamente que o rei, para asse-

21 "Et ideo leges, per quas talia tributa solui precipiuntus, etiam si in illis addatur poena, siue dubio pure poenales dici non possunt, sed morles, sicut sunt aliae de seruandis contractibus, \& implendis promissis, \& in vniversum de reddendo debito, quod vnicuique ex iustitia debetur. Vnde etiam certum est tales leges obligare in conscientia ad soluenda tália tributa, integre, \& sponte, \& sine vlla diminutione, ac fraude; etiam si non pecantur. Quia sunt debita ex iustitia commutatiua, quae secum affert hanc intrisecam obligationem, nisi ex consuetudine, vel scriptura constet, aliam fuisse conditionem pacti seu oneris rebus ipsis impositi: nam tunc illae seruandae sunt, \& ita de his tributis nihil amplius hic dicemus: pertinente enim ad materiam de feudis, \& alijs regalibus, uv vocant". (Suárez, 1613, p. 352, Lib. V, Cap. XIII, 4).

22 "Ratio est, quia verba legis ordinarie sunt praeceptiua, sicut sunt communiter in alij legibus moralibus, quae ad bonum regimen reipublicae ordinantur, ideoque obligant in conscientia, non obstante diectione poenae. Secundo, quia intentio talis esse praesumitur, nisi aliud certo constet morli certitudine, quia (vt dicebam) per poenam volunt Principes augere efficaciam legis, non minuere Et quia per se primo intendunt in effectu consequi tributum sibi, \& communi bono reipublicae necessarium. Vnde est tertia ratio, quia materia tlium legum maxime postulat huiusmodi obligationem, quia est materia iustitiae, \& in re grauissima, ac pertinente ad commune bonum: imo necessaria moraliter ad reipublicae conseruationem, \& gubernationem: ergo illi materiae quasi debetur, \& connaturale est preceptum perse, \& absolute obligans, non tantum sub conditionali pacto sustinendi penam, quod est valde per accidens, \& de se sufficiens ad grauissimum tributorum finem". (Suárez, p. 354, Liv. V, Cap. XIII, 12). 
gurar que se pague o tributo, "pode acrescentar-se the a pena, a qual não diminua a força, \& obrigação do contrato, mas sirva de hua nova coacção, para que os subditos paguem o que por justiça Ihe devem" (Antonil, 1711, p. 155).

Antonil utiliza também outros autores parar fundamentar a sua opinião. Com base nas opiniões de Diego de Avendaño e de Luís de Molina, o autor defende ser justo que "o príncipe tenha alguma parte mais, que os outros particulares em cousas de preço singular, como tem outros bens, ainda quando pareceria ser melhor dallas ao publico" (Antonil, 1711, p. 156). Entre as situações descritas, Antonil menciona os casos dos bens que, em sucessão $a b$ intestato, passam ao fisco real, a pena de perdimento e de confisco de bens e os quintos do ouro. Ao final, e sob esses argumentos, Antonil apresenta as opiniões de Avendaño, Vasquez, Lugo e Molina de que o quinto é obrigação que se deve em consciência. O mesmo argumento sobre o quinto é aplicável ao dízimo, que também era um tributo devido à Coroa, mas, como já se mencionou, em razão das doações papais aos monarcas ibéricos.

Por outro lado, se a obrigação se deve em consciência, o mesmo não se pode dizer da pena. Enquanto a existência de uma obrigação de natureza tributária não estava associada necessariamente à lei, a pena dependia essencialmente do ato normativo para estipular que, nos casos de não observância do dever de pagamento do tributo, seria imposta pena. Consequentemente, a imposição da pena poderia acontecer somente depois de sentença condenatória, já que a pena não decorreria de uma obrigação em consciência. A última frase do capítulo, inclusive, resume essa ideia: "o quinto sempre se deve de justiça, \& a perda da fazendo, \& o degredo, so post sententiam" (Antonil, 1711, p. 159).

É também no final do capítulo que Antonil, ao reafirmar a sua posição de que a obrigação de se pagar o quinto decorre da consciência, relaciona o seu pensamento e as opiniões de Francisco Suárez e de outros juristas e teólogos. Essa referência demonstra claramente que, ao fundamentar a sua opinião sobre o assunto, Antonil buscou construí-la com base no que ele considerava as melhores opiniões sobre o tema, e, neste contexto, tanto melhor seria a opinião quanto maior fosse a autoridade do autor citado. 


\subsection{A construção dos argumentos jurídicos por Antonil}

Essa busca pela construção consistente de uma argumentação convincente marcou a literatura jurídica do Antigo Regime, conforme já mencionado em outros textos $^{23}$. Antonil utilizou primordialmente dois tipos de argumentos para a construção da sua opinião, que seriam as menções à legislação régia e as opiniões de juristas e de teólogos.

De um modo geral, poucas foram as referências à legislação. As Ordenações do Reino aparecem no começo do capítulo, quando se mencionam, na página 146, o Liv. 2, tit. 26, $\S 16$ (que reaparece na página 148) e o tit. 28 do mesmo livro, assim como, na página seguinte o tit. 34 (que reaparece na página 152). Há uma menção (lib. 6, tit. 13, I. 4) da Recopilación de Leyes de Castela, de 1565, na página 148, ou seja, mencionou-se legislação em apenas seis momentos do referido capítulo.

As opiniões de juristas e de teólogos, por outro lado, foram muito mais frequentes. A autoridade de nomes como Francisco Suárez foi decisiva para a construção do argumento central de Antonil. Da lista de citações que se segue abaixo, chama-se atenção para o fato de que os dois autores mais vezes citados nesta parte de Cultura e opulência são considerados "indianos", ou seja, são autores ligados à América hispânica. Solórzano Pereira e Diego de Avendaño foram dois dos mais relevantes juristas do período colonial, e a o acesso às suas obras poucos anos depois da sua publicação por um jesuíta radicado na América Portuguesa só corrobora com a tese de que as suas obras efetivamente circularam no mundo do direito comum.

A tabela a seguir contém uma relação com os nomes dos autores citados ao longo do texto e as respectivas quantidades de vezes em que eles foram mencionados.

\footnotetext{
${ }^{23}$ Entre outros textos, (Cabral, 2017).
} 


\begin{tabular}{|l|l|}
\hline \multicolumn{1}{|c|}{ Autor } & Número de citações \\
\hline Juan de Solórzano Pereira & 10 \\
\hline Diego de Avendaño & 8 \\
\hline Francisco Suárez & 6 \\
\hline Luís de Molina & 5 \\
\hline Padre Vásquez & 4 \\
\hline Juan de Lugo & 3 \\
\hline Joao Baptista Fragoso & 2 \\
\hline Rebello & 2 \\
\hline Pedro Barbosa & 2 \\
\hline Pierre Rebuffi & 2 \\
\hline Cardeal Thuscus & 1 \\
\hline Diego de Covarruvias y Leyva & 1 \\
\hline Diego del Castillo de Villasante & 1 \\
\hline Giuseppe Mascardi & 1 \\
\hline Guido Panciròli & 1 \\
\hline Ignacio de Lasarte y Molina & 1 \\
\hline Jorge de Cabedo & 1 \\
\hline Juan Azor & 1 \\
\hline Juan Garcia de Saavedra & 1 \\
\hline Leonard Lessius & 1 \\
\hline Lucas de Penna & 1 \\
\hline Manuel Álvares Pegas & 1 \\
\hline Martín de Azpilcueta Navarro & 1 \\
\hline Pedro Sanz Morquecho & 1 \\
\hline Prospero Farinacci & 1 \\
\hline Sebastiani Naevi & 1 \\
\hline Tancredus Bononiensis & 1 \\
\hline Tommaso de Vio (Cardeal Caetano) & 1 \\
\hline
\end{tabular}

\section{Uma conclusão}

Mesmo sem ter circulado quando da sua publicação, Cultura e opulência é uma obra que revela grande importância para uma história da literatura jurídica no período colonial e, portanto, para a própria história do direito colonial no Brasil. Como já se mencionou anteriormente, a relevância de uma obra para o estudo da literatura jurídica se revela a partir de duas perspectivas, a saber, o seu impacto enquanto obra, o qual se mede a partir da sua circulação, e a sua construção enquanto obra, a qual pode revelar que o autor teve acesso a uma literatura jurídica e teológica para construir os seus argumentos. 
Como Cultura e opulência não circulou à época da sua impressão, sua relevância reside primordialmente no segundo aspecto, uma vez que, por meio das referências utilizadas por Antonil, é possível perceber claramente que o autor teve acesso a uma quantidade bastante significativa de textos jurídicos e teológicos para construir a sua obra. Pelo período de escrita, o autor estava no Brasil quando elaborou o texto, corroborando com a ideia de que havia um ambiente, ainda que restrito, para a circulação de um direito letrado na América Portuguesa. Esse direito letrado estava intimamente ligado à tradição jurídica europeia, mas que, na América, sofreu um processo de tradução cultural, a fim de resolver os problemas de uma realidade particular ${ }^{24}$.

Por outro lado, não se pode perder de vista que o fato de a obra ter sido recoIhida e proibida de circular não significa que as ideias nela contidas não tenham efetivamente circulado. Textos proibidos circulavam de um modo distinto, que poderia compreender tanto uma circulação clandestina quanto formas diferentes do contato direto com o livro. As ideias contidas em Cultura e opulência, notadamente quanto ao tratamento que se deveria dar aos escravos, efetivamente circularam e se difundiram no ambiente da América Portuguesa. É nesse sentido, por exemplo, que Silvia Lara afirma que, se os livros de Jorge Benci e Antonil praticamente não circularam, o mesmo não se pode dizer das suas ideias, uma vez que a prática demonstraria claramente que a realidade passou a adotá-las com frequência, disseminando-as (Lara, 1988, p. 61). Olhando para a discussão jurídica na obra analisada, não é exagerado afirmar que o ponto central do argumento de Antonil sobre a natureza da obrigação de pagar tributos esteve intimamente relacionado com a tradição do direito comum e com pensamento teológico predominante, os quais foram traduzidos para a realidade colonial.

\section{Fontes primárias}

ANTONIL, André João. 1711. Cultura e opulência no Brasil e suas drogas, e minas. Lisboa, Dislandesiana.

AVENDAÑO, Diego de. 1668. Thesaurus Indicus seu generalis instructor Tomus Primus. Antuerpiae, lacobum Mevrsivm.

CABEDO, Jorge de. 1699. Practicarum observationum sive decisionum Supremi Senatus

\footnotetext{
${ }^{24}$ Sobre o tema, (Foljanty, 2015).
} 
Regni Lusitaniae pars secunda. Antuerpiae, Joannis Baptistae Verdussen.

CASTRO, Gabriel Pereira de. 1621. Decisiones Supremi Eminentissimique Senatus Portugaliae. Ulyssipone, Petrum Craesbeeck.

GAMA, António da. 1683. Decisionum Supremi Senatus Lusitaniae Centuriae IV. Antuerpiae, Joannem Baptistam Verdusen.

GARCIA DE SAAVEDRA, Juan. 1668. De expensis et meliorationibus commentarius. Amstelaedami, Joannem à Ravesteyn.

HESPANHA, António Manuel. 2015. Como os juristas viam o mundo, 1550-1750: direitos, estados, pessoas, coisas, contratos, ações e crimes. Lisboa, Create Space.

LUGO, Ioannis de. 1652. De iustitia et iure tomus primus. Lugduni, Philippi Borde, Laurentii Arnaud \& Claudii Rigaud.

MOLINA, Luis de. 1614. De iustitia et iure tomus primus. Moguntiae, Balthasar Lippius.

PEGAS, Manuel Álvares. 1684. Commentaria ad ordinations Regni Portugalliae. Tomo 9, Ulyssipone, ex Typographia Michaelis Deslandes.

PEREIRA, Juan de Solórzano. 1672. De indiarum iure sive de iusta indiarum occidentalium inquisitione, acquisitione, \& retentione. Tomus primus. Lugduni, Sumptibus Laurentii Anisson.

SUÁREZ, Francisco. 1613. Tractatus de legibus ac Deo Legislatore. Antuerpiae, loanne Keerbergivm.

\section{Bibliografia}

AMBIRES, Juarez Donizete. 2008. Antônio Vieira e Antonil: práticas e representações na América Portuguesa. Projeto História, (37): 95-114.

ANDRADE, Francisco Eduardo de. 2006. A natureza e a gênese das Minas do Sul nos livros de André João de Antonil e Sebastião da Rocha Pita. Revista Brasileira de História, 26(51):171-195.

BRUNNER, Otto. 1959. Land und Herrschaft: Grundfragender territorialen Verfassungsgeschichte Österreichs im Mittelalter. 4 ed., Wien/Wiesbaden, Rudolf M. Rohrer.

CABRAL, Gustavo César Machado. 2017. Literatura jurídica na Idade Moderna: as decisiones no Reino de Portugal (séculos XVI e XVII). Rio de Janeiro, Lumen Juris. . 2016. Thomasius e o direito natural. Sequência, (72):145-167. 
DECOCK, Wim. 2013. Theologians and Contract Law: the moral transformation of the Ius Commune (ca. 1500-1650). Leiden/Boston, Martinus Nijhoff Publishers.

DIAS, Mariza de Araújo. 2012. Os jesuítas e a escravidão africana no Brasil colonial: um estudo sobre os escritos de Antônio Vieira, André João Antonil e Jorge Benci: sécs. XVII e séc. XVIII. Assis, São Paulo, Dissertação de mestrado, Universidade Estadual Paulista, Faculdade de Ciências e Letras de Assis, 100p.

DUVE, Thomas. 2012. Von der Europäischen Rechtsgeschichte zu einer Rechtsgeschichte Europas in globalhistorischer Perspektive. Rechtsgeschichte, (20):-71.

. 2017. Was ist 'Multinormativität'? Einführende Bemerkungen. Rechtsgeschichte, (25):88-101.

FOLANTY, Lena. 2015. Legal transfers as process of cultural translation: on the consequences of a metaphor. Max Planck Institute for European Legal History Research Paper Series, 9.

HESPANHA, António Manuel. 2017. As fronteiras do poder: o mundo dos rústicos. $A$ ordem do mundo e o saber dos juristas: imaginários do antigo direito europeu. Lisboa, Create Space, 2017, p. 199-278.

2017. Pluralismo jurídico e direito democrático: prospetivas do direito no séc. XXI. Lisboa, Create Space.

KELSEN, Hans. 1934. Reine Rechtslehre: Einleitung in die rechtswissenschaftliche Problematik. Leipzig, Deuticke.

LARA, Silvia Hunold. 1988. Campos da violência: escravos e senhores na Capitania do Rio de Janeiro, 1750-1808. Rio de Janeiro, Paz e Terra.

LEITE, Serafim S.I. 1949. História da Companhia de Jesus no Brasil. Tomo VII: assuntos gerais; séculos XVII-XVIII. Rio de Janeiro, Instituto Nacional do Livro.

LUZ, Guilherme Amaral. 2008. A oikonomia do engenho ou o engenho da polis cristã: Prudêncio Amaral, Antonil e o açúcar. Revista do CESP, 28(40):81-94.

MARQUESE, Rafael Bivar. 1999. Administração e escravidão: ideias sobre a gestão da agricultura escravista brasileira. São Paulo, HUCITEC.

. 2004. Feitores do corpo, missionários da mente: senhores, letrados e o controle de escravos nas Américas, 1680-1880. São Paulo, Companhia das Letras.

PESSOA, Raimundo. 2008. O escravo negro nos letrados coloniais: 1633-1758. História Revista, 13(1):223-247. 
PUNTONI, Pedro. 2013. O Estado do Brasil: poder e política na Bahia colonial - 15481700. São Paulo, Alameda, p. 111-146.

SCHWARTZ, Stuart B. 2012. Preface. In: ANTONIL, André João, Brazil at the dawn of the Eighteenth century. Trad. Timothy J. Coates. Darmouth, Massachusetts, Tagus Press, 2012, p.11-14.

SEELAENDER, Airton Cerqueira-Leite. 2017. A longa sombra da casa. Poder doméstico, conceitos tradicionais e imaginário jurídico na transição brasileira do Antigo Regime à Modernidade. Revista do IHGB, Rio de Janeiro, ano 178, (473): 327-424.

SILVA, Andrée Mansuy Diniz. 2007. Introdução. In: ANTONIL, André João, Cultura e opulência do Brasil por suas drogas e minas. São Paulo, EDUSP.

SOUZA, Laura de Mello e. 2006. O sol e a sombra: política e administração na América Portuguesa do século XVIII. São Paulo, Companhia das Letras, p. 84-98.

TAU ANZOÁTEGUI, Victor. 1992. Casuísmo y sistema: indagación histórica sobre el espíritu del Derecho Indiano. Buenos Aires, Instituto de Investigaciones de Historia del Derecho.

TAUNAY, Afonso d'Escragnolle. 1923. André João Antonil e sua obra. São Paulo, Melhoramentos.

VAINFAS, Ronaldo. 1986. Ideologia da escravidão: os letrados e a sociedade escravista no Brasil Colonial. Petrópolis, Vozes.

ZERON, Carlos Alberto de M. R. 2011. O governo dos escravos nas Constituições Primeiras do Arcebispado da Bahia e na legislação portuguesa: separação e complementaridade entre pecado e delito. In: FEITLER, Bruno; SOUZA, Evergton Sales (Org.), A Igreja no Brasil: normas e práticas durante a vigência das Constituições Primeiras do Arcebispado da Bahia. São Paulo, Editora Unifesp, p. 323-354.

Artigo recebido em 22 de outubro de 2017 e aprovado em 07 de janeiro de 2018. 